\title{
Adenopathies in Internal Medicine Etiological Profile and Diagnostic Limits
}

\author{
Michel Assane Ndour ${ }^{1 *}$, Atoumane Faye ${ }^{2}$, Abdoulaye Leye ${ }^{1}$, Boundia Djiba ${ }^{2}$, Maimouna Sow ${ }^{2}$, \\ Sy Baydi Kane², Ngoné Diaba Diack1, Fall Codou Biram1, Yakham Mohamed Leye1, \\ Mouhamed Dieng², Nafy Ndiaye', Léa Marie Kabou ${ }^{3}$, Abdoulaye Pouye ${ }^{2}$ \\ ${ }^{1}$ Department of Internal Medicine/Endocrinology, National Pikine Hospital Center, Dakar, Sénégal \\ ${ }^{2}$ Department of Internal Medicine, Center Hospital Aristide Le Dantec, Dakar, Sénégal \\ ${ }^{3}$ Department of Hematology, Center Hospital Aristide Le Dantec, Dakar, Sénégal \\ Email: *michelassanendour@yahoo.fr, atoufayemi@yahoo.fr, ablayleye@hotmail.com, boundiadjiba@yahoo.fr, \\ mouna89sow@hotmail.fr, baidykane@yahoo.fr, diackngone@gmail.com, biramfall86@gmail.com, leyeyakham@yahoo.fr, \\ sigmadiez@hotmail.fr, fyfynami@yahoo.fr, leassane1@gmail.com, docpouye@yahoo.fr
}

How to cite this paper: Ndour, M.A., Faye, A., Leye, A., Djiba, B., Sow, M., Kane, S.B., Diack, N.D., Biram, F.C., Leye, Y.M., Dieng, M., Ndiaye, N., Kabou, L.M. and Pouye, A. (2017) Adenopathies in Internal Medicine Etiological Profile and Diagnostic Limits. Open Journal of Internal Medicine, 7, 80-96.

https://doi.org/10.4236/ojim.2017.73009

Received: August 23, 2017

Accepted: September 16, 2017

Published: September 19, 2017

Copyright (c) 2017 by authors and Scientific Research Publishing Inc. This work is licensed under the Creative Commons Attribution International License (CC BY 4.0).

http://creativecommons.org/licenses/by/4.0/ (c) (i) Open Access

\begin{abstract}
INTRODUCTION: An adenopathy is a pathological hypertrophy of a lymph node of various etiologies requiring a rigorous approach. Thus we proposed in this work to study the etiological particularities of patients admitted for adenopathy in order to identify their specificities. METHODS: This was an observational study of a transverse and descriptive type, which took place from 1 July 2015 to 30 June 2016 in the internal medicine department of the Aristide Le Dantec national hospital in Dakar. RESULTS: We identified 84 patients, consisted of 46 male and 38 female. The sex ratio was 1.2. The mean age was 37.5 years. The consultation period was on average 2 months with extremes of 1 month and 1 year. The mean hospital stay was 29.2 days with extremes of 1 week and 2 months. The etiologies found were classified into 6 groups. Hemopathies (30.9\%) were dominated by acute leukemia in 8 patients $(9.52 \%)$, non-Hodgkin's lymphoma in 9 patients (9.5\%), Hodgkin's disease in 5 patients (5.9\%). Chronic lymphocytic leukemia was retained in 3 patients (3.5\%) and Castleman disease in 1 patient. Systemic diseases (11.9\%) were divided into lupus disease in 4 patients and rheumatoid arthritis in 4 patients, one case of Sjögren's syndrome and one case of sarcoidosis. Infections were very frequent in our study, found in 34 patients (40.4\%). Tuberculosis was more frequent (27.3\%). The association with HIV was noted in 4 patients. The other infections were pyogenic in 3 patients (3.5\%), HIV in 6 patients (7.1\%), Borrelia and toxoplasma in 1 patient respectively. Cancers (8.3\%) were metastatic of primary tumors including the esophagus, lung, prostate, cavum, stomach, pancreas and breast, one case each. One patient presented lymphadenopathy with inguinal localization, the etiology of which was found to be thromboph-
\end{abstract}


lebitis of the right lower limb. The hystiocytic pathologies $(3.5 \%)$ were all related to lymphohystiocytic activation syndrome (LHAS) secondary to tuberculosis in 2 patients and pyomyositis in 1 patient. The difficulties encountered were mainly the inaccessibility of certain complementary examinations and the delay in obtaining the results. CONCLUSION: Adenopathies are a very common reason for consultation in internal medicine. This study allowed us to draw up the etiological profile of adenopathies in our practice but also to identify the main difficulties which are among other things the inaccessibility of certain complementary examinations.

\section{Keywords}

Adenopathy, Etiologies, Dakar, Diagnostic Limits

\section{Introduction}

Lymph nodes are lymphoid organs in which the immune response develops. An adenopathy (ADP) is a pathological hypertrophy ( $\geq 1 \mathrm{~cm}$ at the lymph node or $\geq 2 \mathrm{~cm}$ at the inguinal level) of a lymph node [1]. Lymphadenopathy is a very common reason for consultation in internal medicine. They generally show an infectious, inflammatory or tumoral process developed in the territory they drain (localized adenopathies) or a more generalized inflammatory or tumoral process (poly adenopathy of infections, leukemias) [2]. Despite the numerous etiologies, the diagnosis is most often based on the anatomopathological study of the ganglion accessible to the biopsy requiring a rigorous diagnostic approach beforehand. In Africa, especially in Senegal, a few cases have been reported with particularities of lymphadenopathy localized in an area [3] [4]. However, etiological research still poses some limitations due to the inaccessibility of certain examinations and even the delay of the complementary examinations.

Thus, in view of these data, we proposed to study the etiological characteristics of patients admitted and followed in internal medicine for adenopathy regardless of its location in order to identify their specificities.

It is within this framework that we initiated this study by recruiting exhaustively all patients followed in the department of internal medicine for lymphadenopathy over a period of one year.

\section{Patients and Methods}

We conducted our study in the Department of Internal Medicine at the Aristide Le Dantec Hospital (HALD) in Dakar. This was a cross-sectional and descriptive observation survey. The study was conducted during the period from 1 July 2015 to 30 June 2016. It consisted of all the patients followed in hospital, in the department of internal medicine. All patients over the age of 16 years with lymphadenopathy were included in the study and hospitalized in the service regardless of their location. A recruitment of all patients received during the period 
and meeting the inclusion criteria was carried out.

The patient was informed of the purpose of our study and consented to its inclusion in our study. He was also aware of his status. The data were collected in strict compliance with medical confidentiality. All of our patients who met the inclusion criteria were collected on a survey card. The clinical features of adenopathies are well noted in the record as well as the associated signs. We also used the standards of the laboratories of biology, biochemistry, bacteriology and parasitology of the HALD and the Pasteur Institute of Dakar where certain biological examinations were carried out.

A questionnaire was submitted to each patient. The data were collected on the basis of a pre-coded, anonymous and self-administered questionnaire. The patient was informed of the subject of our study and his consent requested in view of its inclusion in our study. He was also aware of his diabetes status and the complications he would be exposed to. Data were collected in strict compliance with medical confidentiality.

To determine the size of the sample, this formula: $n=(z)^{2} p(1-p) / d^{2}$. $n=$ sample size; $z=$ confidence level according to the normal centered reduced law (for a confidence level of 95\%, $z=1.96$, for a confidence level of 99\%, $z=$ 2.575); $p=$ estimated proportion of the population with the characteristic (when unknown, $p=0.5$ ); $d=$ tolerated margin of error (for example, the actual proportion is to be $5 \%$ ).

The results were captured and analyzed using an electronic questionnaire developed using SPSS 24.0 software. A double seizure was carried out and the databases obtained were confronted. The cleaning of the file had allowed correction of the errors of entry. The graphics were made using the Excel module of the MS Office 2010 suite. This software was used to calculate frequencies, averages and standard deviations. The bivariate analysis was done using the Chi-square tests (Pearson and Yates) for comparisons of proportions. The comparison of the means was carried out using the Student test. The difference was considered to be statistically significant at $<5 \%$. The odds ratio (OR) surrounded by its confidence interval was used to quantify the strength of the bond. Variables with more than $10 \%$ missing data were not analyzed. The study population was described using variables studied. This descriptive study was done with the calculation of frequencies for the qualitative variables.

\section{Results}

Patients were 46 male and 38 female. The sex ratio was 1.2. The mean age of patients was 37.5 years with a standard deviation of 17.7. The extremes were 16 and 80 years with a median of 34 years. The modal age was 36 years. The most affected age group was between 16 and 35 years old with $31 \%$ between 16 and 25 years of age, $23.8 \%$ between 26 and 35 years of age. Figure 1 shows the distribution of patients by age and gender.

The most represented age group for women was 16 - 25 (42.1\% female) and 


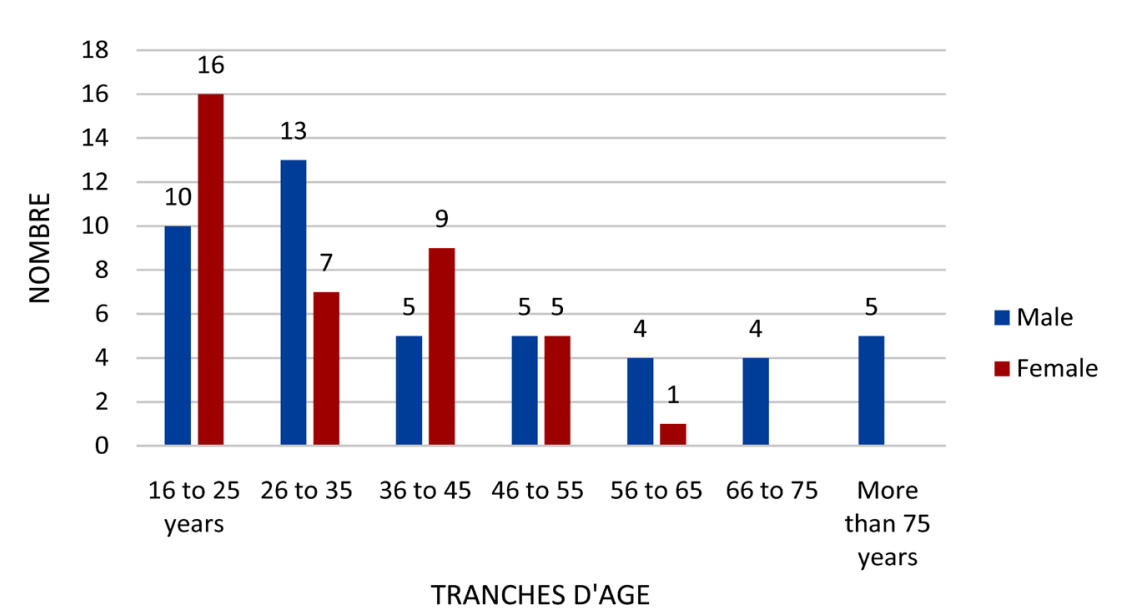

Figure 1. Distribution of patients by age group and gender.

26 - 35 years for men (28.2\%). The average age of women was 29.7 years, lower than that of men, which was 41.30 years $(\mathrm{p}=0.047)$. The consultation period was on average 2 months with extremes of 1 month and 1 year. The mean hospital stay was 29, 2 days with extremes of 1 week and 2 months.

In our patients, 37 (44\%) had a poly macro ADP, 20 (23.8\%) had poly-ADP, 27 (32.1\%) had micro and adenopathies. Sixty-five patients (77.4\%) had more than 4 palpable adenopathies and/or discovered imaging. They are located either in an area (12\%) or mostly in several areas (88\%). The duration of adenopathy was acute in 8 patients (9.5\%), chronic in 63 patients (75\%) and unknown in 13 patients (15.4\%). The chronic course was more frequent in men, 36 patients or $57.1 \%$. These data are reported in Table 1.

In our series, cervical and lateral cervical localization was most frequent in 69 patients $(82.1 \%)$, followed by axillary localization in 60 patients $(71 \%)$. The adenopathies were localized in a single area in $1 / 3$ of the cases $(28.6 \%)$, and multiples gave a polyadenopathy table in 56 patients $(66.6 \%)$.

Table 2 shows the distribution of adenopathies according to their location.

Adenopathies were inflammatory in 38 patients (45.2\%), in 47 patients (56\%), in 7 patients $(8.3 \%)$ and in 2 patients $(2.4 \%)$ in fistulae. These data are shown in Table 3.

ADPs were associated with several signs of fever (65\%), anemic syndrome (71.4\%), and general impairment (82.1\%). The cell profile of the serites was more lymphocytic in 15 patients (17.9\%). The associations are summarized in Table 4.

The hemogram was abnormal in 79 patients (94\%). Anemia was noted in 68 patients (81\%) with an average hemoglobin of $5.3 \pm 1.2 \mathrm{~g} / \mathrm{dL}$. It was inflammatory in 42 patients $(61.7 \%)$. Leukocytosis was observed in 40 patients $(47.6 \%)$ and thrombocytopenia was observed in 27 patients (32.14\%). Thrombocytosis was found in 7 patients. Leucopenia was observed in 12 patients (14.2\%). Agranulocytosis was also observed from the outset in 5 out of 6 patients with neutropenia. 
Table 1. Evolution of adenopathies at admission.

\begin{tabular}{rccccc}
\hline & & Female & Male & Total & Percentage \\
\hline \multirow{3}{*}{ Evolution ADP } & Acute & 3 & 5 & 8 & 9.5 \\
& Chronic & 27 & 36 & 63 & 75 \\
& unknown & 8 & 5 & 13 & 15.4 \\
Total & & 38 & 46 & 84 & \\
\hline
\end{tabular}

Table 2. Distribution of adenopathies according to their seat.

\begin{tabular}{llcc}
\hline & Number & Percentage \\
\hline \multirow{2}{*}{ Cervical } & 17 & 20.2 \\
Axillary & 4 & 4.8 \\
& Inguinal & 3 & 3.6 \\
& Cervical and axillary & 27 & 32.1 \\
& Cervical and abdominal & 10 & 11.9 \\
& Cervical and inguinal & 3 & 3.6 \\
& Axillary, médiastinal and inguinal & 5 & 6 \\
$\quad$ Cervical, axillary and inguinal & 11 & 13 \\
Cervical, axillary, inguinal, épitrochlear & 4 & 4.8 \\
\hline
\end{tabular}

Table 3. Locoregional characters of adenopathies.

\begin{tabular}{cccc}
\hline & Number & Percentage & Percentage accrued \\
\hline Inflammatory & 38 & 45.2 & 45.2 \\
Yes & 46 & 54.8 & 100.0 \\
No & 84 & 100 & \\
Total & & & 56 \\
Tumors & 47 & 56 & 100.0 \\
Yes & 37 & 44 & \\
No & 84 & 100 & \\
Total & & & 100 \\
Compressives & 7 & 8.3 & \\
Yes & 77 & 91.7 & 2.4 \\
No & 84 & 100 & 100 \\
Total & 82 & 100 & \\
Fistulized & 2 & 2.4 & \\
Yes & & 97.6 & \\
No & & & \\
Total & & & \\
\hline
\end{tabular}


Table 4. Signs associated with adenopathies.

\begin{tabular}{lccc}
\hline & Signs & Number & Percentage \\
\hline Splenomegaly & 15 & 17.9 \\
Hepatomegaly & 18 & 21.4 \\
Pulmonary Condensation & & 19 & 22.6 \\
Anemic syndrome & & 60 & 71.4 \\
& ascite & 21 & 25 \\
Serositis & ascite + pleuresy & 11 & 9.5 \\
& pericarditis + pleurisy & 1 & 7.1 \\
& pleurisy & 3 & 1.2 \\
Fever & & 55 & 1.2 \\
Medullary insufficiency syndrome & & 5 & 65.5 \\
Superior cave syndrome & & 1 & 1.1 \\
General state alteration & Oui & 69 & 82.1 \\
\hline
\end{tabular}

Pancytopenia was noted in 6 patients. However, bicytopenia was more frequent in 17 patients (20.2\%). Abnormalities were noted in 16 patients (19\%), the Reed-Sternberg cells identified (in 3 patients) allowed a diagnostic orientation from the outset towards Hodgkin's disease. A proliferation of lymphocytic cells was noted in 4 patients, the presence of blasts in 7 patients and the rest composed of atypical cells. An inflammatory biological syndrome was noted in 57 patients $(67.8 \%)$. The argeenerative character found in 15 patients $(17.8 \%)$ allowed to orient the etiological research towards the medullogram to make certain diagnoses.

On the infectious level, blood cultures were performed in 47 patients (55.9\%). They were positive in 9 of them $(19.1 \%)$ to identify the responsible germ. Cytobacterial examination of urine was negative in 3 patients and positive in a patient isolating Escherichia Coli. Thick drop was negative in our patients except for Borrella Burgdorferi isolate. Retroviral serology was positive in 6 patients (7.14\%). Intradermoreaction to tuberculin (IDRt) was positive in 28 patients (33.3\%). The search for bacilli acido-alcoholo resistant in sputum was positive in 8 patients (9.52\%). Cytobacteriological examination of sputm was performed in 8 patients, it was positive and isolates a germ in 1 patient. Toxoplasmic serology was positive in 1 patient Gen-Xpert was performed in 7 patients but was not contributory.

Immunologically, the specific antibodies were assayed according to clinical directions. Anti-nuclear antibodies were positive in 3 patients (3.5\%), anti-ECT antibodies in 3 patients (3.5\%), rheumatoid factors in 7 patients and anti-DNA antibodies in 2 patients. Thoracic radiography was performed in 80 patients (95.2\%). It showed interstitial syndrome in 32 patients (38\%), cavitary images in 13 patients (15.4\%), bronchial syndrome in 10 patients (11.9\%), atelectasis in 7 
patients (8.3\%), Pleural syndrome in 10 patients (11.9\%), vascular syndrome type pulmonary arteriel hypertension, anterior mediastinal syndrome. The radiograph suspected mediastinal ADP in 4 patients. Pelvic and/or endovaginal abdominal ultrasound was performed in 68 patients is $80.95 \%$. It revealed deep lymph nodes in 10 patients (11.9\%). The diagnosis was also made by ultrasound, confirming the signs associated with adenopathies such as hepatomegaly in 20 patients $(23.8 \%)$, splenomegaly in 17 patients $(20.2 \%)$ with their echogenic character, ascites in 21 patients (25\%). Thoracic CT scanner in 13 patients confirmed the mediastinal localization of adenopathies in 5 patients (5.95\%), diffuse interstitial pneumonitis in 6 patients (7.1\%), pulmonary infectious localization in 10 patients (11.9\%), massive pulmonary embolism following aggressive lymphoma with mediastinal and axillary localization of compressive ADP, pleural effusion in 5 patients (5.9\%). The abdominal thoraco scan was requested as part of the tumor extension. In 8 patients (9.5\%), it showed the primary localization of lymph node metastases in 7 patients (87.5\%).

Lymph nodes were performed in 50 patients is $59.62 \%$; it had already provided diagnostic guidance. It was in favor of tuberculosis (32\%), malignant haemopathy (30\%). The results are summarized in Table 5.

Lymph node biopsy was performed in 45 patients (53.5\%). The diagnosis was confirmed in most patients, tuberculosis in 13 patients (28.8\%), malignant haemopathy in 15 patients (33\%), and metastasis in 7 patients (15.5\%). Biopsy was not performed in 39 patients (46.42\%). Among them, thirteen patients $(15.4 \%)$ did not have the means to do the pathology examination. The data are summarized in Table 6.

Table 5. Summary of abnormalities found at lymph nodes.

\begin{tabular}{lcc}
\multicolumn{1}{c}{ Lymph nodes } & Number & Percentage \\
\hline Non-specific adenopathy & 10 & 20 \\
Necrotizing lymphadenopathy & 3 & 6 \\
Non-specific lymphadenopathy & 1 & 2 \\
Nodal Tuberculosis & 16 & 32 \\
Hodgkin lymphoma & 4 & 8 \\
Extra-hematopoietic lymph node metastases & 4 & 8 \\
Metastasis of a carcinoma & 3 & 6 \\
Reactive lymphoid hyperplasia & 5 & 10 \\
LLC B & 1 & 2 \\
BURKITT Lymphoma & 1 & 2 \\
Diffuse lymphoma with large cell B & 1 & 2 \\
Diffuse range of lymphoid cells & 1 & 2 \\
Not realized & 34 & 100 \\
Total & 84 & \\
\hline
\end{tabular}


Table 6. Summary of abnormalities found at lymph node biopsy.

\begin{tabular}{lcc}
\hline \multicolumn{1}{c}{ Lymph node biopsy } & Number & Percentage \\
\hline Tuberculosis & 45 & \\
Infectious lymphadenopathy & 13 & 28.8 \\
Hodgkin's lymphoma in its nodular sclero form & 2 & 4.4 \\
Hodgkin's lymphoma with mixed cells & 2 & 4.4 \\
Metastases & 1 & 2,2 \\
LLC type B & 7 & 15.5 \\
B cell lymphoma & 2 & 4.4 \\
Lymphoma BURKITT & 3 & 6.6 \\
Plastic and follicular hyperplasia & 3 & 6.6 \\
Sarcoidosis & 2 & 4.4 \\
Castleman & 1 & 2.2 \\
Non-contributory & 1 & 2.2 \\
Not realized & 8 & 17 \\
Total & 39 & 100 \\
\hline
\end{tabular}

Immunophenotyping was performed in 7 patients. He confirmed the diagnosis of 6 cases of malignant hemopathies including 3 Hodgkin's disease. The medullogram was performed in 15 patients (17.8\%). The diagnosis of acute leukemiawasretained in 8 patients $(9.5 \%)$, medullarymetastasis in 2 patients (2.3\%), SALH in 3 patients patients, 1 case of vitamin B 12 deficiency and another normal.

The etiologies found were diverse, depending on the clinical course of adenopathies and associated signs. First-line complementary examinations provided diagnostic guidance. Certain additional examinations (lymph node biopsy, immunophenotyping, medullogram ...) had made it possible to better classify the etiologies by retaining 6 groups: malignant haemopathies, systemic diseases, infections, neoplastic and vascular causes and histiocytic pathologies. Table 7 summarizes the different etiologies of the adenopathies found in our patients.

Eighty-one of our patients (96.4\%) had a well-established diagnosis. This had made it possible to begin symptomatic but also etiological treatment. Various means were used (analgesics, antibiotics, chemotherapy, immunosuppressants including corticosteroids, anticoagulant).The mean etiological management time was 26 days with extremes of 5 days and 4 months, this being related to the recovery of the results especially the lymph node biopsy. The progression was favorable, marked by remission in 67 patients (79.7\%). Ten patients died and seven patients were lost to follow-up.

In the course of this study, the diagnosis made it possible to detect some difficulties: 
Table 7. Characteristics of the different etiologies found in our study.

\begin{tabular}{|c|c|c|c|}
\hline Etic & ogical framework & $\mathrm{N}(\%)$ & Specials \\
\hline \multirow{10}{*}{$\begin{array}{l}\text { Malignant } \\
\text { hemopathies } \\
(26 \text { patients) }\end{array}$} & Hodgkin's disease & $5(5.9)$ & $\begin{array}{l}\text { Lymphocyte depletion: } 1 \text {; Mixed cellularity: } 1 \\
\text { Scleronodular: 2; Poppema nodular paragranuloma: } 1\end{array}$ \\
\hline & Diffuse large cell lymphoma B & $4(4.7)$ & $\begin{array}{l}2 \text { HIV field cases; } 1 \text { case with mediastinal lymph nodes; } 1 \text { case with serum } \\
\text { localization }\end{array}$ \\
\hline & T lymphoma & $1(1.1)$ & Associated medullary location \\
\hline & Burkitt lymphoma & $3(3.5)$ & 1 case of Burkitt leukemia noted \\
\hline & Lymphoide acute leukemia & $2(2.3)$ & 2 younger cases; Diagnosis in the medullogram \\
\hline & Myeloid acute leukemia type 1 & $2(2.3)$ & \\
\hline & Myeloid acute leukemia type 5 & $4(4.7)$ & $\begin{array}{l}2 \text { cases Leukemia Myeloid Chronicle accused, } 2 \text { cases of Leukemia Acute } \\
\text { Myeloid de novo }\end{array}$ \\
\hline & Chronic lymphoblastic leukemia & $3(3.5)$ & 1 case of splenic villous lymphoma, 1 prolymphocyte leukemia \\
\hline & Myeloproliferative Syndrome & $1(1.1)$ & Leukemia Myeloid Chronic acutization? \\
\hline & Castleman's Disease & $1(1.1)$ & Suspicion/result of 2nd biopsy for confirmation not recovered \\
\hline \multirow{4}{*}{$\begin{array}{l}\text { Systemic diseases } \\
\text { (10 patients) }\end{array}$} & Primary Sjögren Syndrome & $1(1.1)$ & \\
\hline & Rheumatoid arthritis & $4(4.7)$ & $\begin{array}{l}1 \text { case of Felty; } 1 \text { associated with } 1 \text { secondary Sjogren Syndrome; } 2 \text { isolated } \\
\text { cases }\end{array}$ \\
\hline & Lupus disease & $4(4.7)$ & 1 case associated with 1 tuberculosis and 1 with Hodgkin's lymphoma \\
\hline & sarcoidosis & $1(1.1)$ & Ganglionic and pulmonary localization \\
\hline \multirow{5}{*}{$\begin{array}{l}\text { Infections } \\
\text { (34 patients) }\end{array}$} & $\begin{array}{l}\text { Bacterial pyogenic } \\
\text { lymphadenopathy }\end{array}$ & $3(3.5)$ & Germs: staphylococcus aureus and haemolytic beta streptococcus, borrelia \\
\hline & Tuberculosis & $23(27.3)$ & $\begin{array}{l}15 \text { cases multifocal tuberculosis, } 4 \text { associated with HIV, } 1 \text { scrofuloderm, } 3 \\
\text { isolated }\end{array}$ \\
\hline & HIV infection & $6(7.1)$ & 2 cases HIV 1, 4 cases HIV 2, 4 cases stage IV WHO \\
\hline & Lyme disease & $1(1.1)$ & Borrelia, using thick gout \\
\hline & toxoplasmosis & $1(1.1)$ & Ganglionic and cerebral localization, positive toxoplasmic serology \\
\hline $\begin{array}{l}\text { Solid neoplasms } \\
\text { (7 patients) }\end{array}$ & Lymph node metastases & $7(8.3)$ & $\begin{array}{l}\text { Pancreas, CBP, gastric, prostatic, cavum, breast, esophagus, } 2 \text { suspected cases } \\
\text { of malignancy with primary location not found, } 2 \text { cases of spinal cord } \\
\text { metastases }\end{array}$ \\
\hline Vascular causes (1) & Phlebitis & 1 & $\begin{array}{l}1 \text { patient with thrombophlebia of the right infant; Inguinal localization of } \\
\text { ADPs }\end{array}$ \\
\hline Histiocytosis (3) & LHAS & $3(3.57)$ & 2 cases secondary to multifocal tuberculosis, 1 on pyomyositis \\
\hline \multicolumn{2}{|c|}{ Causes not found in 3 patients } & & $\begin{array}{l}\text { Biopsy and non-contributory immunohistochemistry for } 2 \text { patients, } 1 \text { death } \\
\text { before exploration }\end{array}$ \\
\hline
\end{tabular}

- The consultation period was delayed and the length of hospitalization was long;

- The painlessness of chronic adenopathies and the lack of financial means of our patients lengthened the consultation period and the duration of hospitalization;

- The quantiferon test is not very accessible due to the recurrent lack of reagents in our public hospitals and its dearness in private laboratories; 
- The histological examination of the costly surgical specimen was the responsibility of patients who are unfortunately mostly indigent;

- The reading of the pieces by the anatomopathologists who are few in number is long delaying the establishment of the diagnoses;

- The realization of immunophenotyping was difficult because of its cost and therefore its inaccessibility for the majority of our patients despite its indication;

The technique of ganglion biopsy is performed by the surgeons; which limits its practice if the latter are not available.

\section{Discussion}

Lymph nodes are a frequent reason for consultation in internal medicine. The etiological profile of adenopathies has been studied in our regions, in particular in their cervical localization and/or associated with other localizations [4]. Our study which was prospective observational descriptive, for one year, aimed to follow the patients in order to identify in addition to the etiological profile, the limits encountered in the establishment of the diagnoses.

In our series, the patients consisted of 46 male and 38 female. The sex ratio was 1.2. The mean age of patients was 37.5 years with a standard deviation of 17.7. These data are comparable to those found by NDONGO et al. [4] on the etiological profile of cervical adenopathies, which reported a sex ratio of 1.2 with a younger mean age of 34 years. A similar study in elderly subjects found a male predominance with an average age of 74 years justified by the target of the study [2].

The consultation period was on average 2 months in our series. The same delay found by other African authors [5] [6] differs from that of Western authors [7] which rarely exceeds 2 months (less than 2 months often).This long delay could be explained by the more often painless character of chronic adenopathies and the lack of financial means of our patients. The latter lack social security coverage, cover the costs of hospitalization, explorations and treatment. These reasons make the patients stay for a long time without consulting. Moreover, there is difficult access to specialized consultancy in our countries, insufficient qualified staff and lack of reference at the higher level. The same reasons explain the length of hospital stay.

In our study, 39 patients had a history and terrain that was related to ADP. These personal and/or family histories (smoking, HIV, malignant haemopathies ...) partly oriented the etiological research of ADPs. This shortened the duration and the cost of the explorations, given the very limited means of our patients and consequently an efficient management.

ADPs were chronic in 63 patients (75\%). This chronicity of ADP was explained on the one hand by the often painless character; Patients not considering the need to consult since they kept their daily activities, others by financial inaccessibility. Indeed the latter constituted a brake helped in this by the lack of specialists accustomed to take charge of ADP. The unknown duration of ADP in 13 
patients was related to the fact that they were not large and did not require consultation. Other African authors [8] [9] found this macro and polyadenopathy (> $80 \%)$ chronic from the first consultation. The high frequency of this polyadenopathy is a function of the etiology involved (tuberculosis for one of the series), but also of the long period of consultation of the patients, which favors the attack of several lymph node groups. Lymphadenopathy was indeed isolated in some cases, however, multiple sites giving a polyadenopathy score were more common in 56 patients $(66.6 \%)$. These data remain variable in the series and depend essentially on the studies. They are comparative to a study on lymphoma or poly adenopathies were classically predominantly cervical [10]. The cervical localizations located down are evocative of tumoral cause also as reported in certain series [11].

Adenopathies were inflammatory in 38 patients, is $45.2 \%$, tumors in 47 patients, 56\%, compressive in 7 patients $(8.3 \%)$. These data were similar in the same study carried out to identify the etiology of cervical ADPs associated or not with other localizations where $34.27 \%$ were tuberculous ADPs [8], with lymphomatous and tumor ADPs Mostly tumoral. The significant inflammatory character of ADPs could be explained by the frequency and predominance of infectious pathology in our regions.

The alteration of the general state reported in other series [11] [12] was also more frequent than in our study as signs such as fever and serites. The frequency of the associated signs that are sometimes in front of the scene is explained by the polymorphic character of the etiologies found in our regions thus delaying the orientation towards the specialists. However, the identification of the associated signs always retains its relevance in the etiologic orientation in order to select the relevant complementary examinations [13].

First-line biological explorations strongly influenced the demand for further etiologic diagnosis. The inflammatory character $(61.7 \%)$ was almost constant in most of the inflammatory pathologies of our cohort in particular infections and diseases of systems. These data are in agreement with those reported in other studies, or inflammatory syndrome occupies an important place in biological abnormalities [12] [14]. Cytopenia is due to the high prevalence of hemopathies in our series, but also to systemic diseases and spinal cord injury in certain etiologies such as acute leukemia, tuberculosis and so on.

By identifying Reed-Sternberg cells (3 patients), proliferation of lymphocytic cells (4 patients) and blastosis (7 patients), this contribution of blood count and blood smear are reported by other authors [15] [16].

The impairment of renal function in our series was $20.2 \%$. This high prevalence could be explained by the delay in the consultation of our patients who often come to the stage of the resonance of their diseases. However, most cases were functional. The significant presence of proteinuria in 19\% of our patients was due mainly to the renal impairment of systemic diseases, excluding urinary tract infections treated with appropriate antibiotherapy.

The positivity of adenosine desaminase and IDRt respectively in $15.4 \%$ and 
33.3\% reinforced the presumptive arguments in our patients with tuberculosis. Our data are comparable to those found in the cohorts of BAMA G [12] and BARRY [7], who found $90 \%$ and $100 \%$, respectively, but also by SOUDRE [17] in Burkina and VIGNIKIN [8] 30\% and 100\%. This test remains a good orientation in our context where the quantification is not very accessible due to the recurrent lack of reagents in our public hospitals and its dearness in private laboratories. The immunodepression noted in some of our patients by the HIV infection explains the negativity of the IDRt [18]. Imaging is essential for the research of deep ADPs but also for the etiological orientation. The improvement of the imaging techniques now makes it possible to obtain spatial resolutions of the order of a millimeter and to improve the resolutions in contrast [2].

Our chest X-ray data are comparable to those found in several studies, where radiography is still important because of its accessibility, especially in regions where certain pathologies, particularly infectious diseases, are present. In view of all these abnormalities suggestive of infectious, systemic or tumor pathologies, we can say that this examination therefore remains of routine interest in areas where several pathologies still exist. The decentralization of radiography services with continuing medical education in radiography for hospitals would contribute to early diagnosis in general.

Ultrasound was also a good examination of etiologic orientation. The combination of ultrasound and fine needle cytopuncture (used in our study in few patients) confirmed its feasibility and efficacy in the initial exploration of cancer patients with high sensitivity $(77 \%-98 \%)$ and a specificity of $100 \%$ in the experimented as reported in some series [19]. It remains an excellent technique for exploring superficial lymph nodes with good sensitivity. However, it has some limitations for deep ganglionic chains [20].

The adenogram was a simple, painless technique with undeniable advantages. However, fine needle cytopuncture deserves careful interpretation and must take into account the size, localization and lymph node consistency. The place of cytopunction in the etiologic assessment of adenopathies is currently recognized but must be supplemented by biopsy [19]. However, the high unsatisfactory sampling rate in our series ( 10 of the 50 cases) is also described in the literature. This may justify resuming this rapid, easy and cost-effective review [21].

The lymph node biopsy is the examination of choice for any acute or subacute lymphadenopathy to offer the pathologist an excellent piece of analysis. Most authors emphasize this privileged position of ganglion biopsy in the diagnosis of chronic adenopathies [4] [13] [16] and [22].

However, its realization often encounters some difficulties in our practice which are not negligible:

Patients did not always accept the biopsy and deliberately refused the procedure $(4.7 \%)$.

The expensive costs of the histological examination of the surgical specimen were borne by the patients who are unfortunately mostly destitute (15.4\%). 
The very insufficient number of pathologists in Senegal (six in number and all based in Dakar) increased the time between completion of the lymph node biopsy and the achievement of results. This delay was 2 months - 15 days on average with the consequence the loss or the degradation of certain surgical specimens sometimes due to bad conditions of conservation which could negatively affect the interpretation of the results and consequently the diagnostic management and therapeutic.

These difficulties tend to limit the practice of glandular biopsy which remains the examination of choice, indispensable for the diagnosis of chronic adenopathy. In certain cases and according to the etiological orientation, it will be supplemented by an immunohistochemical study or a bacteriological study with isolation of the germ and antibiogram.

Immunophenotyping because of its cost and consequently its inaccessibility for the majority of our patients despite its indication, its realization was difficult. However, it keeps all its interest in the diagnosis of certain diseases especially malignant hematological diseases. This could be supplemented by cytogenetics and molecular biology. These latter techniques are mainly used in the diagnosis of lymphoid pathology and for prognostic purposes [13].

The medullogram was used to diagnose acute leukemia and LHAS. It is an accessible examination, an inescapable contribution in the diagnosis of certain malignant haemopathies.

As in the literature, the etiologies found were diverse, depending on the clinical evolution of adenopathies and the associated signs. First-line complementary examinations provided diagnostic guidance. Concerning malignant haemopathies, from a clinical point of view, sixteen patients had a tumor syndrome. Diagnostic delay was delayed. It was on average 39 days. The mean age was 38 years with extremes of 16 and 68 years. A clear male predominance (57.1\%) was noted with a sex ratio of 1.3. Our data are similar to those found in the literature. BAMA G [12] who conducted a study of the etiologies of cervical adenopathies involving 296 patients found a clear male predominance both for Hodgkin's disease where all the patients were of masculine gender as for the Non-Hodgkin's lymphoma (NHL) where 9 of the 16 patients were male. The average age in his study was 25 years for Hodgkin's disease and 33 years for NHL. AUDRIEU et al. [23] found this male predominance with two peaks: one around 30 years and the other after 50 years. The diagnosis of cases of acute leukemia in the medullogram noted in our series was oriented by the tumor syndrome associated with the medullary insufficiency syndrome in a context of alteration of the general state which was quasi-constant (82.1\%). This easy and accessible examination on the patient's bed remains essential for the diagnosis of acute leukemia even if the translocations have not been detected. These data are similar to those described in the literature [24]. However biopsy in some cases may not be contributory as it was in our series where in 8 patients the biopsy is not contributory despite a histological study supplemented by an immunohistochemical study in the famous 
large laboratories. Physical examination and evolution will thus constitute important elements of surveillance to look for a lesser sign that could guide the etiology.

Systemic diseases were not so weak as they were retained in 10 patients (11.9\%). The adenopathies, through the biopsy would make it possible to reinforce these pathologies. For the rheumatoid arthritis, the table and the immunological assessment were largely lendable, the biopsies allowed to rule out another associated hypothesis. The adenopathies found in lupus diseases were more bulky and multiple (4 of 4 patients) compared to patients with rheumatoid arthritis. A predominantly female, (7 of 11 patients), the average age was 36 years in our series, data widely reported in the literature [13]. For sarcoidosis, the ganglionic localization was also epitrochlear, among other things, histology revealed an epithelioid and gigantocellular granuloma without caseous necrosis. These characteristics are well described in the literature [13].

Infections were frequent ( 40.4 dominated in our series by tuberculosis (27.3\%). Several studies in Africa showed similar results [4]. For YU et al [25], in Asia, tuberculous adenopathies of the neck represent the main chronic cervical masses with 64 patients recorded in 1994. Despite tuberculosis vaccination with biliary of Calmette and Guerin (BCG), which is systematic and mandatory at birth, tuberculosis continues to be prevalent worldwide [26] and particularly in resource-limited countries. It is experiencing a revival since the advent of HIV. Clinically, adenopathies were inflammatory and chronic in 17 patients with predominant cervical and axillary localization (15 patients). The multifocal character (serous, pulmonary, and cutaneous involvement, etc.) in 15 patients constituted guidance in favor of tuberculous disease, especially since sputum was positive in half (8 patients). The lymph node biopsy was conclusive in 13 patients. Four of them were co-infected with HIV. The frequent combination of lymphoma and tuberculosis, as well as the occurrence of opportunistic infections and conditions such as lymphoma in patients living with HIV, should be performed with lymph node biopsy, even in cases of bacilli acido alcohoolo resistant sputum positivity. The high prevalence of infections in our context reflects the low socio-economic level of our population even though most of these diseases are cosmopolitan.

The tumor character of the adenopathies associated with other signs of organic or visceral involvement led the diagnosis towards solid neoplasia. The metastatic character of adenopathies was confirmed by histology. The average age found in our series was 41.2 years. It was inferior to those found by SARINI [27] in the West which was around the fifth decade. This difference is likely to be related to life expectancy in developed countries, which is higher than that of developing countries, but also to the early diagnosis of certain neoplasias before the stage of metastasis; On the other hand, chronic recurrent infections in our regions that can make the bed of certain neoplasias. The male predominance observed in our series (sex ratio 1.5) is found by others of authors [27]. It is explained by the 
fact that the subject of the masculine gender is much more exposed to certain risk factors, such as alcohol-tobacco association, poor oral hygiene and certain chronic infections. Endoscopy retains its full value in diagnostic research before any chronic adenopathy of primitive appearance [28] especially when the patient has a sign of digestive appeal. It makes it possible to find the primitive lesion in $85 \%$ of the cases. In other cases, a lymph node dissection followed by an anatomical examination may be performed [29].

A vascular cause was noted in our study in a patient with lymphadenopathy with inguinal localization. The diagnosis was thrombophlebitis of the right lower limb. The adenopathies were acute. They were not biopsied. The progression was favorable with a regression of the inflammatory character of the leg, the adenopathies by cons were residual. He did not have enough recoil to follow completely the evolution of these adenopathies. This residual character of the adenopathies and the rapid rearrangement of the inguinal ADPs makes all the difficulty of the diagnosis. However, the biopsy remains discouraged in these cases, the clinical picture and its evolution play an important role in the management of inguinal ADPs. These data are described in the literature [1] [16].

Histiocytic pathologies were all related to LHAS (3 patients) secondary to tuberculosis and pyomyositis. A case of disseminated intravascular coagulation was demonstrated in the 2 tuberculous patients with LHAS. The medullogram keeps all its interest in assisting the diagnosis.

\section{Conclusion}

Lymphadenopathy is a very common reason for consultation in internal medicine. They may indicate an infectious, inflammatory or tumoral process developed in the territory from which they provide drainage (localized lymphadenopathy) or from a more generalized inflammatory, systemic or tumoral process (poly-adenopathy of viral infections, systemic diseases, of leukemias). The etiologies are diverse, which requires a rigorous diagnostic approach. During our study, we encountered some difficulties. This was mainly due to the inaccessibility of certain additional examinations linked to the high cost but also to the fact that most of them were not carried out on site in Senegal, which considerably extended the diagnostic delay.

\section{Conflict of Interest}

The authors have nothing to disclose.

\section{References}

[1] Bernard, J., et al. (1998) Diagnosis of Adenopathy. Abbreviated Hematology. Edition MASSON, 238-240.

[2] Rousset, H., et al. (2008) Superficial Lymph Nodes. Difficult Diagnosis in Internal Medicine. Edition Maloine, 33-43.

[3] Elidrissi, A.M., Benjelloun, H., Zaghba, N. and Yassine, N. (2017) Etiological Profile of Mediastinal Adenopathies. 21st French-Speaking Congress of Pulmonology, 
Marseille, 27-29 January 2017. https://doi.org/10.1016/j.rmr.2016.10.483

[4] Ndongo, S., Pouye, A., Ka, M.M. and Diop, T.M. (2011) Etiological Profile of Cervical Adenopathy in Internal Medicine. The Journal of Internal Medicine, 32S, S91-S191. https://doi.org/10.1016/j.revmed.2011.03.154

[5] Piquet, J. and Chevalier, D. (1990) Cervical Adenopathies Encyclopedia Medico-Surgical. Elsevier, Paris, 20-870-A-10, 6 p.

[6] Tolo, A., Toure, O. and Toure, A.H. (1999) Epidemiological, Clinical and Evolutionary Profile of Malignant Non-Hodgkin's Lymphomas (Non Burkitt) in African Black. Medicine of Black Africa, 46, $6 \mathrm{p}$.

[7] Barry, B. and Gehanno, P. (1998) Cervical Adenopathies of Infectious Origin. Cahiers d'ORL, 33, 329-336.

[8] Vignikin-Yehouessi, B., Voduohe, S.J. and Agbokanzo, A.D. (1999) 81 Cases of Lymph Node Tuberculosis of the Neck at the CNHU of Cotonou (1980-1999). Medicine of Black Africa, 46, 8 p.

[9] Tamini, M.M. (1990) Anatomo-Clinical and Biological Study of Chronic Cervical Adenopathies in Burkina Faso (About 136 Cases Encountered at the CHN-YO). Thesis of Medicine, 10, $65 \mathrm{p}$.

[10] Brown, J.R. and Skarin, A.T. (2004) Clinical Mimics of Lymphoma. Oncologist, 9, 406-416. https://doi.org/10.1634/theoncologist.9-4-406

[11] Bazemore, A.W. and Smucker, S.H. (2004) Atypical Cellular Disorders. American Society of Hematology. Education Program, 1, 283-296.

[12] Bama, G. (2003) Epidemiological, Clinical and Para-Clinical Aspects of Chronic Cervical Adenopathies in CHU-YO's ORL and CCF Departments. These N 422003.

[13] Reyt, E. and Righini, C. (1999) Cervical Adenopathies. Encyclopédie médico-chirurgicale (Elsevier, Paris), Otorhinolaryngology, 20-870-A-10.

[14] Sakande, B. (1986) Contribution to the Study of the Etiological Diagnosis of Chronic Cervical Adenopathies in Burkina Faso. Thesis of Medicine. Niamey, 15, 115 p.

[15] Abdellaoui, F., Ben Abdallah, O. and Zayene, A. (2012) The Adenopathies of the Elderly: Etiological Profile and Prognosis. The Journal of Internal Medicine, 33S, A90-A198.

[16] Sacre, K. and Papo, T. (2008) Superficial Lymph Nodes. In: Rousset, H., Vital-Durant, D., Dupond, J.L. and Pavic, M., Eds., Difficult Diagnosis in Internal Medicine, Maloine, Paris, 33-43.

[17] Soudre, R.B., Tiendrebeogo, H., Sakande, B. and Aulin, B. (1988) Epidemiological and Clinical Aspects of 27 Tuberculous Adenitis. Inter-FacAfrique n05-1988.

[18] Ngilimana, P. (1995) Tuberculosis in HIV-Positive People in Central Africa. Annals of Pathology (Paris), 15, 38-44.

[19] Saboorian, M.H. and Ashfa, Q.R. (2001) The Use of Fine Needle Aspiration Biopsy in the Evaluation of Lymphadenopathy. Seminars in Diagnostic Pathology, 18, 110-123.

[20] Haberal, I., Celik, H., Göçmen, H., Akmansu, H., Yöruk, M. and Ozeri, C. (2004) Which Is Important in the Evaluation of Metastatic Lymph Nodes in Head and Neck Cancer: Palpation, Ultrasonography, or Computed Tomography? Otolaryngology-Head and Neck Surgery, 130, 197-201. https://doi.org/10.1016/j.otohns.2003.08.025

[21] Rammeha, S., et al. (2014) Cervical Lymph Node Function: Factors Influencing Failure Rate. Revue de Stomatologie et de Chirurgie Maxillo-faciale, 115, 85-87. 
[22] Berthou, C. (2006) Superficial and Deep Lymphadenopathy. Leukemia-Espoir.

[23] Andrieu, J.M. and Colonna, P. (1997) Evaluation, Treatment and Surveillance of Hodgkin's Disease. Edition ESTEM, Paris.

[24] Choi, J.W., Kim, S.S., Kim, E.Y. and Heran, M. (2006) Peripheral T-Cell Lymphoma in the Neck: C T Findings of Lymph Node Involvement. AJNR, 27, 1079-1082.

[25] Yu, L. (1994) Cervical Tuberculous Lymphadenitis: CT Findings. Journal of Computer Assisted Tomography, 18, 370-375. https://doi.org/10.1097/00004728-199405000-00006

[26] Belembaogo, E., Moussavou-Kombila, J.B., Nzenze, J.R. and Abiome, R. (1997) Tuberculosis Efficacy and Tolerance about 104 Cases. Medicine of Black Africa, 44, 8-9.

[27] Sarini, J., Coche, D., Kara, A. and Ton Von, J. (1998) The Apparently Primitive Cervical Adenopathies. The Books of O.R.L., 27, 11-15.

[28] Mondain, M., Guerjer, B. and Crampete, L. (1989) Cervical Pathology and Oncology: Primary Malignant Adenopathy of the Neck: About 33 Cases. The Books of O.R.L., 14, 23-32.

[29] Trotoux, J. and Luboinski, B. (1999) Cervical Ganglionic Recesses. Encyclicopedia. Medico-Chirugical. ENT, Fasc. 20872 A10.

\section{Submit or recommend next manuscript to SCIRP and we will provide best} service for you:

Accepting pre-submission inquiries through Email, Facebook, LinkedIn, Twitter, etc. A wide selection of journals (inclusive of 9 subjects, more than 200 journals)

Providing 24-hour high-quality service

User-friendly online submission system

Fair and swift peer-review system

Efficient typesetting and proofreading procedure

Display of the result of downloads and visits, as well as the number of cited articles

Maximum dissemination of your research work

Submit your manuscript at: http://papersubmission.scirp.org/

Or contact ojim@scirp.org 